\title{
A Micromechanical Composite Approach for Finite Element Crashworthiness Simulation
}

Narciso Tolosana, David Ranz, and Óscar Gracia

SISPRA Ltd., Zaragoza, Spain

Jesús Cuartero

University of Zaragoza, Zaragoza, Spain

Antonio Miravete

ICMA, Zaragoza, Spain

\begin{abstract}
The present article deals with micromechanical composite modeling. Both, analytical and computational micromechanics approaches are described as well as micromechanical modeling of damage. Based on micromechanics of failure theory, a user subroutine including a progressive damage algorithm is programmed for finite element analysis. Three theoryexperiment correlations of tubes under a three point bending test have been carried out using the bi-phase material model developed along this project. These studies include three ply schedules. Keywords: composite materials, micromechanics, representative volume element, simulation, progressive damage, failure, finite element analysis.

Received 20 Mar 2015; accepted 07 Jul 2015.

Address correspondence to Narciso Tolosana, SISPRA Ltd., Zaragoza, Spain. E-mail:

ctolosa@sispra.com
\end{abstract}




\section{Introduction}

Many industrial and engineering materials as well as the majority of biological material are inhomogeneous, i.e., they consist of dissimilar constituents (-phases") that are distinguishable at some (small) length scale. Each constituent shows different material properties and/or material orientations and may itself be inhomogeneous at some smaller length scale(s). Inhomogeneous materials (also referred to as microstructured, heterogeneous or complex materials) play important roles in materials science and technology. Well-known examples of such materials are composites, concrete, polycrystalline materials, porous and cellular materials, functionally graded materials, wood, and bone.

The behaviour of inhomogeneous materials is determined, on the one hand, by the relevant materials properties of the constituents and, on the other hand, by their geometry and topology (the phase arrangement"). Obviously, the availability of information on these two counts determines the accuracy of any model or theoretical description. The behaviour of inhomogeneous materials can be studied at a number of length scales ranging from sub-atomic scales, which are dominated by quantum effects, to scales for which continuum descriptions are best suited. This paper concentrates on micromechanical models for heterogeneous materials. The use of these models puts a lower limit on the length scales that can be covered with the methods discussed here, which typically may be taken as being of the order of $1 \mu \mathrm{m}[1]$.

For a composite laminate composed of multiple plies with different angles under certain mechanical and thermal loading conditions, the stress and failure analysis loop often starts from and then ends at the ply, which has homogenized material properties. 
In a micromechanical approach, the loop is extended to include each constituent: mechanical properties of a ply can be calculated from mechanical properties of fibre and matrix, while the stress distribution in fibre and matrix can be calculated from the ply stress. In order to express the micro structure of one ply in terms of fibre and matrix, an appropriate model is needed.

Actually, a representative volume element (RVE) or unit cell has been used for decades among researchers. With this model, the micro level (fibre and matrix) is directly related to the macro level (ply).

Most structural materials present one dominant physical failure process upon deformation (e.g., void nucleation, growth and coalescence in ductile metals or shear bands formation in polymers) and the simulation of failure only has to include this micromechanism. On the contrary, FRPs present several different physical failure mechanisms and the dominant one depends on the loading conditions. Fracture due to tensile stresses parallel to the fibres is controlled by the tensile fracture of the fibres, while compressive stresses along the fibres lead to fracture by fibre kinking in compression, a mechanism which mainly depends on the fibre misorientation and the matrix shear strength.

Tensile fracture perpendicular to the fibres is brittle and controlled by the fracture of the polymeric matrix and of the fibre-matrix interface, while fracture caused by compressive stresses perpendicular to the fibres or by shear is accompanied by large deformations as a result of the non-linear response of the matrix when subjected to compression and/or shear. Finally, interply delamination is another typical failure mechanism in FRPs due to the thermo-elastic mismatch between adjacent plies with different orientation. 
Hence, accurate models of fracture of FRPs have to include all these micromechanisms and the complex interaction among them because they coexist in the same laminate subjected to one type of load as a result of the different orientation of the fibres in each ply. For instance, intraply matrix cracks (which propagate parallel to the fibres) are very often the origin of interply delaminations, while it is well known that the compressive strength parallel to the fibres is severely reduced in the presence of shear stresses [2].

The degradation scheme presented here is a new approach to carry out simulations of composite structures under crash conditions in an accurate way. The election of the appropriate failure criteria proposed here along with degradation procedure constitutes an innovation to predict the behaviour of composite structures for non-linear applications. Numerical results for three point bending of three composite tube configurations under crash conditions have been obtained and compared to experimental results, with good correlation data. These results underscore the accuracy from the current micromechanical model and the combination of the proposed micromechanics of failure and property degradation methodologies.

A major advantage of this novel approach is the determination of the sequence of failure in terms of the constituents, predicting which one -failure, matrix or interface- fails first, second,... and which one is associated to the final failure. The standard ply-based approach cannot provide this valuable information.

\section{Micromechanical approach and representative volume element}

The approach presented in this paper is based on the theory of micromechanics of failure and on the assumption that initial ply failure is produced by failure of any of its constituents, i.e. fibre, matrix or interface [3]. The theory states that a macro stress state of a ply induces a micro stress 
state on its components that must be evaluated in order to know if failure occurs at constituent level. For this purpose, the concept of stress amplification factors based on linear stress-strain relation is needed. These amplification factors relate macro stresses to micro stresses for constituents [4].

On the macroscopic scale, all engineering constants of a ply reflect the overall response of this fibre-matrix system to mechanical and thermal loadings. In order to obtain effective material properties and the stress distribution in continuous fibre reinforced composite materials at the microscopic level; three-dimensional finite element analysis for a representative volume element is used, since it can provide relatively high accuracy.

The stress-strain relation for a unidirectionally reinforced ply (UD ply) at macro level can be expressed as shown in Eq. (1).

$$
\bar{\sigma}=\bar{C} \bar{\varepsilon}
$$

The correlations between micro strain $\varepsilon_{\text {mech }}$ at any internal point within fibre or matrix and macro strain along with temperature are formulated in Eq. (2).

$$
\varepsilon_{\text {mech }}=M_{\varepsilon} \bar{\varepsilon}_{\text {mech }}+A_{\varepsilon} \Delta T
$$

Where $M_{\varepsilon}$ and $A_{\varepsilon}$ indicate strain amplification factors for macro mechanical strain and temperature increment at that point, respectively, and $\bar{\varepsilon}_{\text {mech }}$ represents the macromechanical strain.

For both, micro and macro mechanical strains, Eq. (3) holds.

$$
\varepsilon_{m e c}=S \sigma \quad, \quad \bar{\varepsilon}_{m e c}=\bar{S} \bar{\sigma}
$$


Where $\mathbf{S}$ is the local compliance matrix at a certain point of the unidirectional ply and $\sigma$ denotes the micro stress at the same point. $\bar{S}$ denotes the global compliance matrix and $\bar{\sigma}$ the macro stress.

Combining equations (2) and (3) we reach Eq. (4).

$$
S \sigma=M_{\varepsilon} \bar{S} \bar{\sigma}+A_{\varepsilon} \Delta T
$$

Multiplying by the inverse matrix of $\mathbf{S}$ produces Eq. (5).

$$
\sigma=M_{\sigma} \bar{\sigma}+A_{\sigma} \Delta T, \quad M_{\sigma}=S^{-1} M_{\varepsilon} \bar{S} \quad A_{\sigma}=S^{-1} A_{\varepsilon}
$$

Where $\mathbf{M}_{\sigma}$ and $\mathbf{A}_{\sigma}$ are named stress amplification factors for macro mechanical stress and temperature increment, respectively. These matrices vary for each material point and depend on material properties, geometrical factors, so analytical calculation is discarded.

To determine the elements of both matrices a finite element analysis is preferred. The finite element model of the unit cell (or RVE) used in this work is composed of 10879 nodes and 9600 elements (Figure 1). Periodic boundary conditions are applied to ensure the correct behaviour of a further multi cell model, producing that nodes on opposite faces of the cell undergo similar displacements (as expressed on Eq. 6).

$$
u_{i}^{+j}-u_{i}^{-j}=c_{i}^{j} \quad(i, j=x, y, z)
$$

Where $u_{i}^{+j}$ and $u_{i}^{-j}$ represent the displacements of a pair of nodes with the same coordinates in other directions except the j-direction. $c_{i}^{j}$ is constant, so all pairs of nodes have the same difference of displacement in the i-direction.

Constituents properties are also needed to complete the finite element model. The interface is assumed to be perfectly bonded. 
Although hexagonal fibre packing is applied to the unit cell in this work, considerations on different packing schemes and comparison with randomly placed fibres inside the composite material can be found in [5]. Figure 2 represents the stress distribution in the unit cell when a $\sigma_{11}=1 \mathrm{MPa}$ stress (fibre direction) is applied.

Figures 3 and 4 show the stress distribution in the unit cell when a $\sigma_{22}=1 \mathrm{MPa}$ stress (transverse direction) and a $\sigma_{12}=1 \mathrm{MPa}$ shear stress are applied, respectively.

Developing the relation between micro and macro stresses, we can obtain the distribution of stress amplification factors by applying unitary macroscopic tractions and checking the nonunitary micro stresses induced, as shown in Eq. (7).

$$
\left(\begin{array}{l}
\sigma_{1} \\
\sigma_{2} \\
\sigma_{3} \\
\sigma_{4} \\
\sigma_{5} \\
\sigma_{6}
\end{array}\right)=\left[\begin{array}{cccccc}
M_{11} & M_{12} & M_{13} & M_{14} & 0 & 0 \\
M_{21} & M_{22} & M_{23} & M_{24} & 0 & 0 \\
M_{31} & M_{32} & M_{33} & M_{34} & 0 & 0 \\
M_{41} & M_{42} & M_{43} & M_{44} & 0 & 0 \\
0 & 0 & 0 & 0 & M_{55} & M_{56} \\
0 & 0 & 0 & 0 & M_{65} & M_{66}
\end{array}\right]_{\sigma}\left(\begin{array}{l}
1 \\
0 \\
0 \\
0 \\
0 \\
0
\end{array}\right) \rightarrow\left(\begin{array}{l}
\sigma_{1} \\
\sigma_{2} \\
\sigma_{3} \\
\sigma_{4} \\
\sigma_{5} \\
\sigma_{6}
\end{array}\right)=\left(\begin{array}{c}
M_{11} \\
M_{21} \\
M_{31} \\
M_{41} \\
0 \\
0
\end{array}\right)
$$

- $\quad \mathrm{M}_{11}$ is given by $\sigma_{1}$

- $M_{21}$ is given by $\sigma_{2}$

- and so on

All the amplification factors needed can be calculated by this method. An example of the variation of amplification factors at each material point of the unit cell for the submatrix $M_{11}-M_{33}$ is shown in Figure 5. This figure illustrates how a macro stress affects several components in the micro stress tensor.

Although a linear behaviour is considered for constituents at initial stage, non-linearities arise when constituents fail, causing a non-linear behaviour for the laminate. In the approach 
presented here, this non-linear behaviour is modelled by the degradation of mechanical properties when failure of a given constituent is detected.

To be able to determine which constituent is responsible of failure, separate failure criteria must be provided for fibre, matrix and interface.

\section{Fibre failure criterion}

A quadratic failure criterion incorporating first-order and second-order stress invariants is usually preferred to evaluate the effect of multi-axial stresses, but for simplicity, the maximum longitudinal stress failure criterion in Eq. (8) is preferred.

$$
-C_{f}<\sigma_{x}<T_{f}
$$

$T_{f}$ and $C_{f}$ are longitudinal tensile and compressive strengths of the fibre. This simplification is based on the fact that the fibre is the major component in supporting the longitudinal tensile load, while the matrix strengths are more important in transverse and shear loads.

\section{Matrix failure criterion}

A modified version of von Mises failure criterion suggested by Christensen [6,7] is adopted for the matrix in Eq. (9). This formula shows that the matrix failure depends not only on the deviatoric stress invariant but also on the volumetric stress invariant, due to the difference between tensile and compressive stress for matrix materials.

$$
\frac{\sigma_{V M}^{2}}{C_{m} T_{m}}+\left(\frac{1}{T_{m}}-\frac{1}{C_{m}}\right) I_{1}=1
$$

$T_{m}$ and $C_{m}$ are the tensile strength and compressive strength of the matrix, respectively, and $\square_{V M}$ and $I_{1}$ are von Mises equivalent stress and the first stress invariant of micro stresses at a point within matrix, respectively. 


\section{$\underline{\text { Interface failure criterion }}$}

The typical interface failure is caused by debonding or detachment between fibre and matrix. The fibre-matrix interface features traction-separation behaviour [8], so the failure criterion considered takes the form in Eq. (10).

$$
\left(\frac{\left\langle t_{n}\right\rangle}{Y_{n}}\right)^{2}+\left(\frac{t_{s}}{Y_{s}}\right)^{2}=1
$$

Where $t_{n}$ and $t_{s}$ are normal (perpendicular to the interface) and shear (tangential to the interface) interfacial tractions, with $Y_{n}$ and $Y_{s}$ being their corresponding strengths. The angle brackets (Macaulay brackets) imply that a pure compressive normal traction does not contribute to interface failure.

\section{Subroutine flow chart}

To apply this approach, a subroutine has been programmed in FORTRAN. The subroutine is based on a VUSDFLD subroutine for the finite element software ABAQUS [9]. This type of subroutine allows the user to define field variables at a material point for an ABAQUS/Explicit analyses.

The defined field variables are functions of time or of any of the available material point quantities. This subroutine will be called at all material points of elements for which the material definition includes user-defined field variables, and can also be used to introduce solutiondependent material properties since such properties can be easily defined as functions of field variables. This type of subroutine can also update solution-dependent state variables.

The objective of the subroutine is to evaluate micromechanical criteria for the constituents, and apply degradation on mechanical properties in case the criteria are met.

A flowchart of the subroutine developed is shown in Figure 6. 
The input file includes all the model, material and boundary conditions definitions. In the material definition section, user defined variables are created and degradation behaviour is introduced. The subroutine reads state variables for each element at any material point and calculates the amplified stresses. Evaluation of failure criteria for each constituent follows, and if any of the criteria are met, degradation is applied by reducing properties depending on which constituent is causing failure. The process is repeated until the iterations specified in the input file are reached. This way, elements failing due to fibre, matrix or interface failure can be tracked.

\section{Theory-Experiment Correlation}

To validate the approach presented in this paper, three theory-experiment correlation studies have been performed with tubes made of glass/epoxy and three different stacking sequences by the filament winding process.

The experimental test set-up is shown in Figure 7. It corresponds to a typical three point bending test. The diameter of the tube is $200 \mathrm{~mm}$ and its length is $590 \mathrm{~mm}$.

The other specifications in figure are:

$\mathrm{d}_{1}=80 \mathrm{~mm}, \mathrm{~d}_{2}=50 \mathrm{~mm}, \mathrm{~b}=380 \mathrm{~mm}$ and $\mathrm{v}=1 \mathrm{~mm} / \mathrm{s}$

The computational analysis was carried out using ABAQUS/Explicit version 6.11-2. The finite element model of the tube consists of 3750 Nodes and 3700 Shell Elements of S4R type.

Although it is demonstrated that mechanical properties of composite materials vary at high strain rates, the low velocity of the actuator in the tests described here make this effect negligible [10]. The properties for the isotropic glass fibre used in the finite element analysis are shown in Table 1. 
Epoxy resin properties are shown in Table 2 and the interface strengths considered for glass/epoxy are in Table 3.

The finite element analysis of the unit cell for different values of fibre volume fraction generates the lamina properties shown in Table 4. These values are in agreement with properties calculated using typical micromechanical formulae (see Eq. 11, where $f$ and $m$ denote fibre and matrix, respectively).

$$
\begin{array}{lc}
E_{1}=E_{f 1} v_{f}+E_{m} v_{m} & \frac{1}{E_{2}}=\left(\frac{1}{E_{f 2}}\right) v_{f}+\left(\frac{1}{E_{m}}\right) v_{m} \\
\frac{1}{G_{12}}=\left(\frac{1}{G_{f 12}}\right) v_{f}+\left(\frac{1}{G_{m}}\right) v_{m} & v_{12}=v_{f 12} v_{f}+v_{m} v_{m}
\end{array}
$$

Property degradation methods usually relate fibre failure to longitudinal modulus decay, while matrix and interface failures produce degradation on transverse modulus. The degradation factors heavily affect the predicted curve slope and maximum load peak. In order to fit experimental curves, degradation scheme applied in GFRP tubes considers that fibre failure causes degradation in longitudinal lamina modulus $\left(E_{1}\right)$ to $10 \%$ of its initial value. Higher values of this factor caused an increased slope for the predicted load-displacement curve, and lower values decreased too much the initial slope.

Matrix failure causes degradation in longitudinal lamina modulus to $20 \%$ and transversal lamina modulus $\left(\mathrm{E}_{2}\right)$ to $2 \%$. Finally, interface failure causes transversal lamina modulus to be reduced to $10 \%$ of its initial value. These degradation parameters affect the maximum value reached by the curve before decreasing the loading force. Higher degradation produces a lower strength value. 
Setup 1-GFRP: 3P bending of GFRP tube with fibres at $\left[ \pm 10^{\circ}\right]_{2}$

First configuration of GFRP consists of a tube with two layers at $\pm 10^{\circ}$. The thickness of each layer is $0.865 \mathrm{~mm}$ and the fibre volume fraction is $v_{f}=63.065 \%$.

Five specimens were tested, and the resultant boundary curves for all the test curves are shown in Figure 8. The predicted curve from finite element analysis with user subroutine is compared to experimental results also in Figure 8.

The deformed state of the tube at the end of the finite element analysis is also compared to one of the specimens after test in figure 8 . It can be observed that the tube is flattened or squashed prior to bending.

Setup 2-GFRP: $3 P$ bending of GFRP tube with fibres at $\left[ \pm 10^{\circ} / 90^{\circ}\right]$

Second configuration of GFRP consists of a tube with a layer at $\pm 10^{\circ}$ of thickness $0.95 \mathrm{~mm}$ and two layers at $90^{\circ}$ of thickness $0.4725 \mathrm{~mm}$ each. The volume fraction is $v_{f}=55.654 \%$.

The curve obtained with finite element analysis with user subroutine is compared to experimental results in figure 9 (five tubes were also tested).

Contrary to setup 1 , in this setup it can be observed that the tube undergoes bending, and the edges of the tube remain with circular shape.

Setup 3-GFRP: 3P bending of GFRP tube with fibres at $\left[ \pm 30^{\circ} / 90^{\circ}\right]$

Third configuration of GFRP consists of a tube with a layer oriented at $\pm 30^{\circ}$ (thickness 0.912 $\mathrm{mm}$ ) and a layer at $90^{\circ}$ (thickness $0.456 \mathrm{~mm}$ ). The fibre volume fraction is $v_{f}=59.267 \%$.

Theoretical curve and boundary test curves (resultant from five tubes tested) for this set-up are compared in figure 10. In this set-up the tube is also bended, but the edges are less open than in set-up 2 and the circular shape is lost. 
The comparison between maximum load predicted by the model in this paper and experimental results in terms of test mean, upper and lower bound values is shown in table 5 .

\section{Discussion and Conclusions}

The graphical comparison of curves shows a good agreement between experimental and simulation results in general terms. The behaviour of a composite tube subjected to three point bending has been reproduced by the finite element analysis using a user subroutine developed with a micromechanical approach.

The main advantage of this micromechanical approach is the capability of get the information about the sequence of failure in terms of the constituents occurring during simulation. Using the current subroutine is possible to find out what constituent is causing a finite element failure. In all three set-ups the interface is the first constituent to fail, followed by the matrix. Fibre is the last constituent presenting failure. This information is very useful to determine what component -fiber, matrix or interface- needs to be enhanced to increase the value of the first-ply-failure.

The first set-up was more difficult to fit. This is probably due to the fact that the experimental tubes become totally flattened.

\section{Acknowledgements}

All the presented work was carried out within the project MATISSE funded by European Commission's 7th Framework Programme.

\section{Funding}

The authors would like to acknowledge the MATISSE partner Forschungsgesellschaft Kraftfahrwesen mbH Aachen, who run the experimental work presented in this paper. 


\section{References}

[1] S. Forest, G. Cailletaud, D. Jeulin, F. Feyel, I. Galliet, V. Mounoury, and S. Quilici, Introduction au calcul de microstructures, Méc. Indust., 3:439-456, 2002.

[2] P. Wright, X. Fu, I. Sinclair, S.M. Spearing, Ultra High Resolution Computed Tomography of Damage in Notched Carbon Fibre-Epoxy Composites, Journal of Composite Materials 42, 1993-2002, 2008.

[3] S.K. Ha, K.K. Jin, Y. Huang, Micro-Mechanics of Failure (MMF) for Continuous Fibre Reinforced Composites, Journal of Composite Materials, 42(18): 1873-1895, 2008.

[4] K.K. Jin, Y. Huang, Y.H. Lee, S.K. Ha, Distribution of Micro Stresses and Interfacial Tractions in Unidirectional Composites, Journal of Composite Materials, 42(18): 1825-1849, 2008.

[5] S.K. Ha, K.K. Jin, Y. Huang, Effects of Fibre Arrangement on Mechanical Behaviour of Unidirectional Composites, Journal of Composite Materials September 2008 42: 1851-1871, 2008.

[6] R.M. Christensen, A Comprehensive Theory of Yielding and Failure for Isotropic Materials, Journal of Engineering Materials and Technology, 129(2): 173-181, 2007.

[7] R.S. Raghava, R.M. Caddell, G.S.Y. Yeh, The Macroscopic Yield Behaviour of Polymers, Journal of Material Science, 8: 225-232, 1973.

[8] P.P. Camanho, C.G. Davila, D.R. Ambur, Mixed-Mode Decohesion Finite Elements for the Simulation of Delamination in Composite Material, NASA-TP-211041, 2001.

[9] Abaqus Analysis User's Manual, Abaqus Version 6-11. 
[10] G.C. Jacob, J.M. Starbuck, J.F. Fellers, S. Simunovic, R.G. Boeman, Strain rate effects on the mechanical properties of polymer composite materials, Journal of Applied Polymer Science 94(1):296 - 301, 2004. 


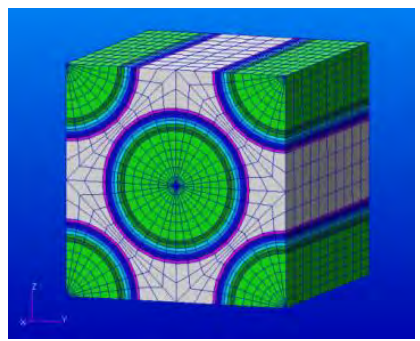

Figure 1. Finite element model of the unit cell. 


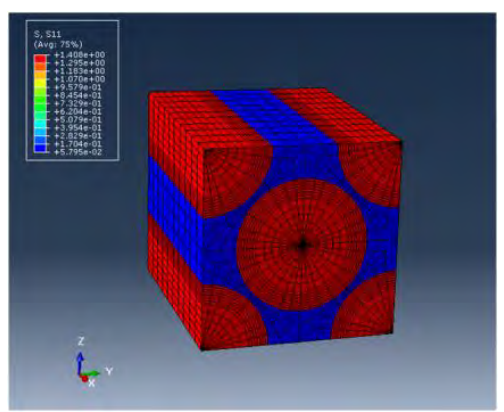

Figure 2. Stress distribution in the unit cell when a ?11 stress (fibre direction) is applied. 


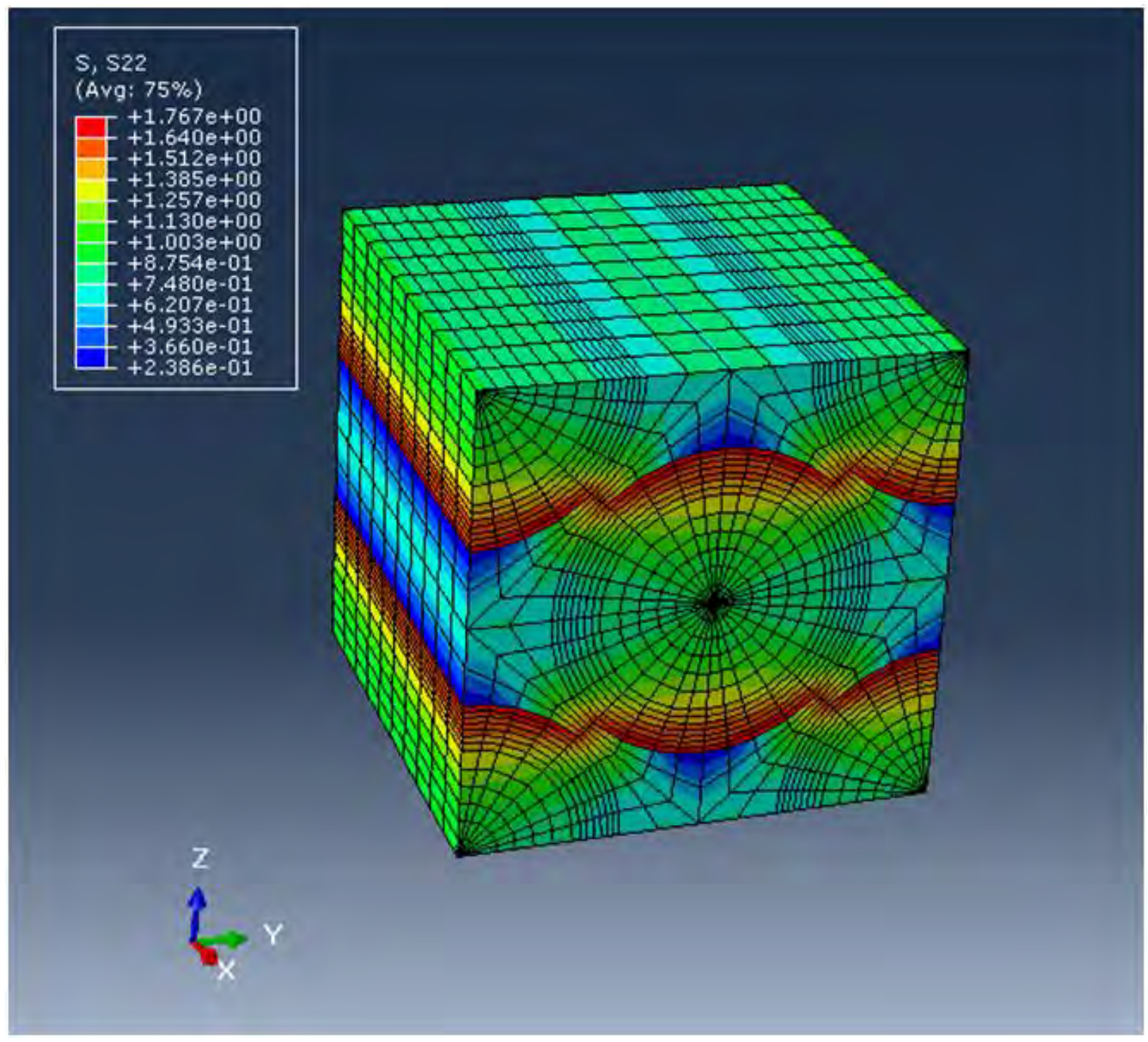

Figure 3. Stress distribution in the unit cell when a ?22 stress (transverse direction) is applied. 


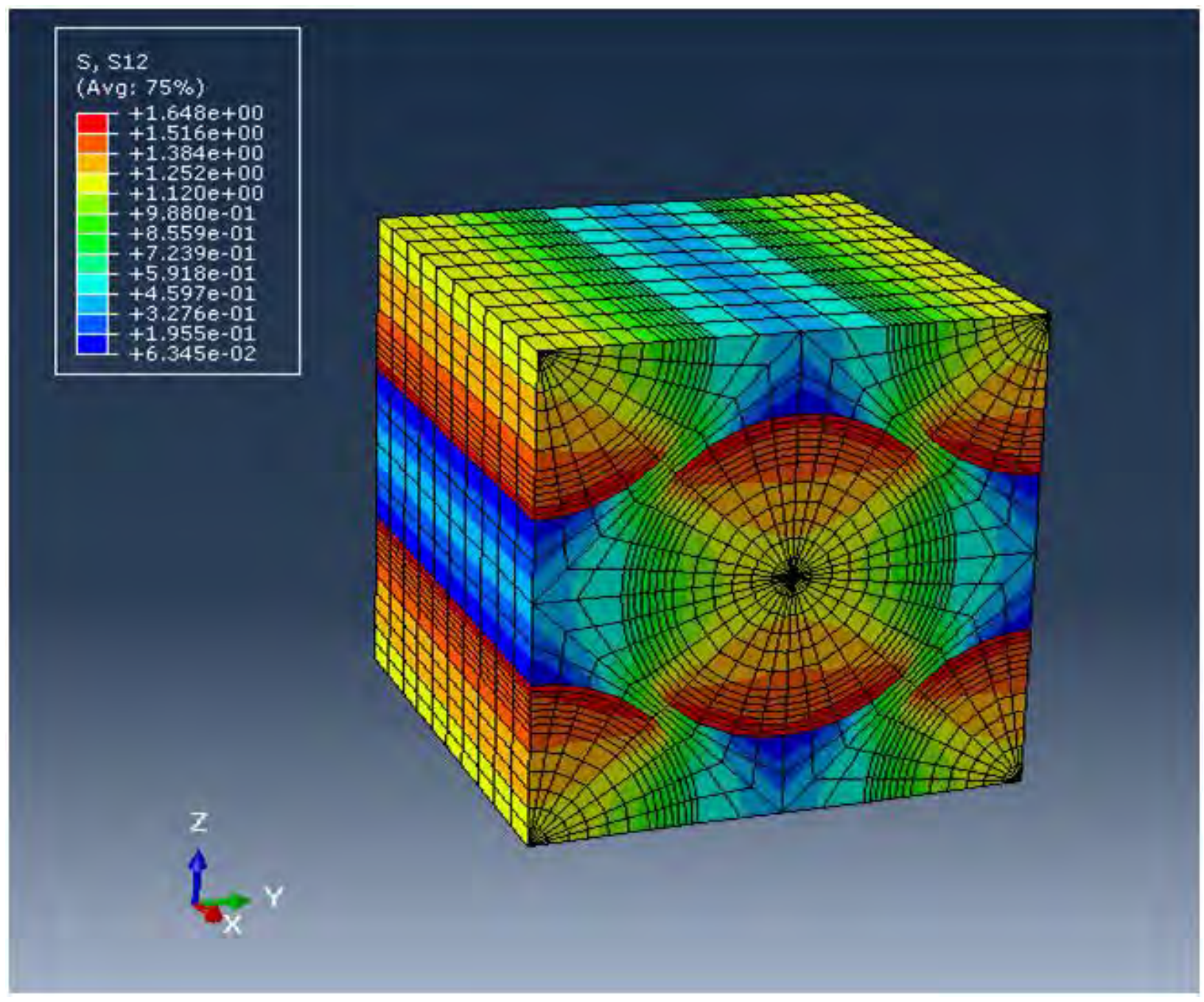

Figure 4. Stress distribution in the unit cell when a ?12 shear stress is applied. 


$$
\left[\begin{array}{cccccr}
M_{11} & M_{12} & M_{13} & M_{14} & 0 & 0 \\
M_{21} & M_{22} & M_{23} & M_{24} & 0 & 0 \\
M_{31} & M_{32} & M_{33} & M_{34} & 0 & 0 \\
M_{41} & M_{42} & M_{43} & M_{44} & 0 & 0 \\
0 & 0 & 0 & 0 & M_{55} & M_{56} \\
0 & 0 & 0 & 0 & M_{65} & M_{66}
\end{array}\right]
$$
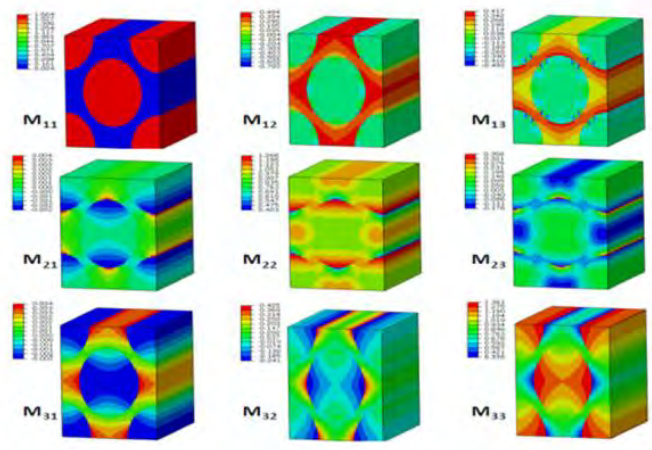

Figure 5. Distribution of the Mij submatrix in the unit cell for $i, j=1,2,3$. 


\begin{tabular}{|c|c|}
\hline Abaqus Input File & \\
\hline Model, materials and $\mathrm{BC}$ & VUSDFLD \\
\hline & Read element state \\
\hline Creation of three user & variables \\
\hline defined variables & \\
\hline$\sqrt{1}$ & Calculate constituent \\
\hline Start iterations & stresses by means \\
\hline & $\begin{array}{l}\text { of stress } \\
\text { amplification factors }\end{array}$ \\
\hline Degradation of & \\
\hline $\begin{array}{c}\text { material properties if } \\
\text { failure criteria are } \\
\text { met }\end{array}$ & $\begin{array}{l}\text { Evaluate different } \\
\text { failure criteria for }\end{array}$ \\
\hline Next iteration & interface \\
\hline 2 & \\
\hline END & \\
\hline
\end{tabular}

Figure 6. Subroutine flow chart. 


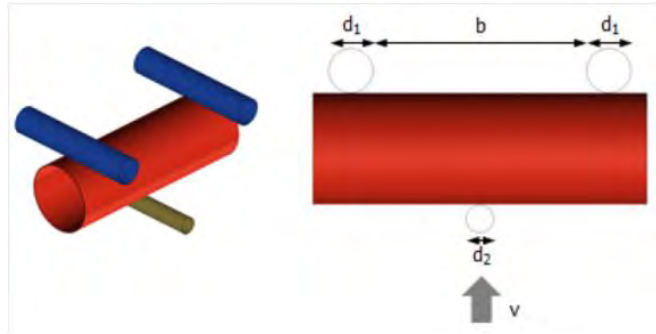

Figure 7. Experimental test set-up. 


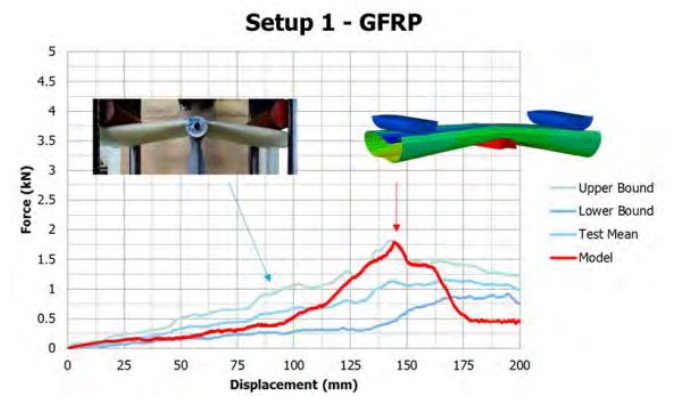

Figure 8. Force-displacement curve of set-up 1 GFRP finite element model compared to experimental results. 


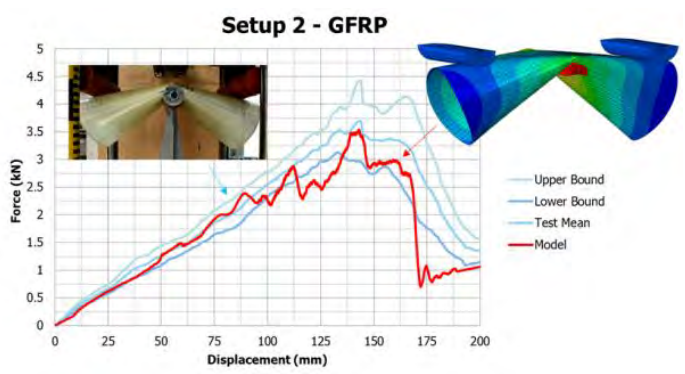

Figure 9. Force-displacement curve of set-up 2 GFRP finite element model compared to experimental results. 


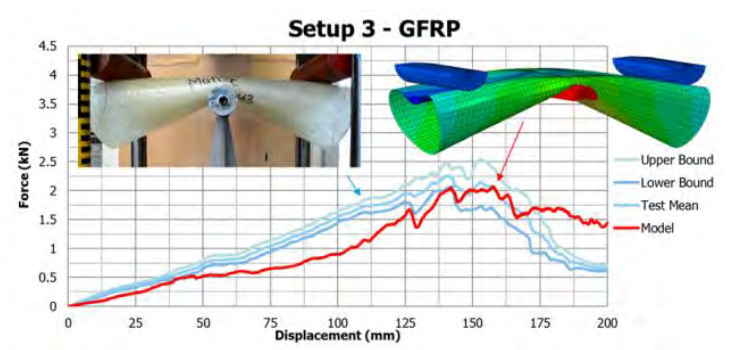

Figure 10. Force-displacement curve of set-up 3 GFRP finite element model compared to experimental results. 
Table 1. Glass fiber mechanical properties

\begin{tabular}{|l|l|l|}
\hline Young's Modulus & $\mathrm{E}_{\mathrm{f}}$ & $82 \mathrm{GPa}$ \\
\hline Shear Modulus & $\mathrm{G}_{\mathrm{f}}$ & $\begin{array}{l}34.16 \\
\mathrm{GPa}\end{array}$ \\
\hline Poisson's Coefficient & $v_{\mathrm{f}}$ & 0.2 \\
\hline Tensile Strength & $\mathrm{T}_{\mathrm{f}}$ & $2.05 \mathrm{GPa}$ \\
\hline Compression Strength & $\mathrm{T}_{\mathrm{c}}$ & $1.3 \mathrm{GPa}$ \\
\hline
\end{tabular}


Table 2. Epoxy mechanical properties

\begin{tabular}{|l|l|l|}
\hline Young's Modulus & $\mathrm{E}_{\mathrm{m}}$ & $3.3 \mathrm{GPa}$ \\
\hline Shear Modulus & $\mathrm{G}_{\mathrm{m}}$ & $1.2 \mathrm{GPa}$ \\
\hline $\begin{array}{l}\text { Poisson's } \\
\text { Coefficient }\end{array}$ & $v_{\mathrm{m}}$ & 0.35 \\
\hline Tensile Strength & $\mathrm{T}_{\mathrm{m}}$ & $0.12 \mathrm{GPa}$ \\
\hline $\begin{array}{l}\text { Compression } \\
\text { Strength }\end{array}$ & $\mathrm{T}_{\mathrm{m}}$ & $0.18 \mathrm{GPa}$ \\
\hline
\end{tabular}

Table 3. Normal (Yn) and shear (Ys) interface strengths

\begin{tabular}{|l|c|c|}
\hline & $\mathrm{Y}_{\mathrm{n}}$ & $\mathrm{Y}_{\mathrm{s}}$ \\
\hline Glass/epoxy & $40 \mathrm{MPa}$ & $90 \mathrm{MPa}$ \\
\hline
\end{tabular}


Table 4. Lamina properties for different fiber volume fractions

\begin{tabular}{|c|c|c|c|c|c|}
\hline & $\% \mathrm{vf}$ & $\mathrm{E}_{1}(\mathrm{GPa})$ & $\mathrm{E}_{2}(\mathrm{GPa})$ & $\mathrm{G}_{12}(\mathrm{GPa})$ & $v_{12}$ \\
\hline Setup 1 & 63.065 & 52.93 & 8.36 & 3.12 & 0.255 \\
\hline Setup 2 & 55.654 & 47.10 & 7.08 & 2.64 & 0.266 \\
\hline Setup 3 & 59.267 & 49.94 & 7.65 & 2.85 & 0.261 \\
\hline
\end{tabular}

Table 5. Maximum load prediction vs experimental results

\begin{tabular}{|l|c|c|c|}
\cline { 2 - 4 } \multicolumn{1}{c|}{} & \multicolumn{3}{c|}{ Maximum Load (kN) } \\
\multicolumn{1}{c|}{ Setup 1 } & \multicolumn{1}{c|}{ Setup 2 } & \multicolumn{1}{c|}{ Setup 3 } \\
\hline $\begin{array}{l}\text { Test Upper } \\
\text { Bound }\end{array}$ & 1.816 & 4.435 & 2.549 \\
\hline Test Mean & 1.156 & 3.698 & 2.256 \\
\hline $\begin{array}{l}\text { Test Lower } \\
\text { Bound }\end{array}$ & 0.916 & 3.135 & 2.071 \\
\hline $\begin{array}{l}\text { Model } \\
\text { Prediction }\end{array}$ & 1.793 & 3.540 & 2.073 \\
\hline
\end{tabular}

